Article

\title{
Experimental and Numerical Investigation of an Overheated Aluminum Droplet Wetting a Zinc-Coated Steel Surface
}

\author{
Marius Gatzen ${ }^{1,+}$, Peer Woizeschke ${ }^{1, *}$ (D) Tim Radel $^{1}$, Claus Thomy $^{1}$ and Frank Vollertsen ${ }^{1,2}$ \\ 1 BIAS-Bremer Institut für Angewandte Strahltechnik GmbH, Klagenfurter Str. 5, 28359 Bremen, Germany; \\ marius.gatzen@simufact.de (M.G.); radel@bias.de (T.R.); thomy@bias.de (C.T.); info-mbs@bias.de (F.V.) \\ 2 Faculty of Production Engineering, University of Bremen, Klagenfurter Str. 5, 28359 Bremen, Germany \\ * Correspondence: woizeschke@bias.de; Tel.: +49-421-2185-8029 \\ + Present Address: Department of Welding Simulation, Simufact Engineering GmbH, Tempowerkring 3, \\ 21079 Hamburg, Germany.
}

Received: 3 November 2017; Accepted: 28 November 2017; Published: 1 December 2017

\begin{abstract}
Wetting steel surfaces with liquid aluminum without the use of flux can be enabled by the presence of a zinc-coating. The mechanisms behind this effect are not yet fully understood. Research results on single aluminum droplets falling on commercial galvanized steel substrates revealed the good wetting capability of zinc coatings independently from the coating type. The final wetting angle and length are apparently linked to the time where zinc is liquefied during its contact with the overheated aluminum melt. This led to the assumption that the interaction is basically a fluid dynamic effect of liquid aluminum getting locally alloyed by zinc. A numerical model was developed to describe the transient behavior of droplet movement and mixing with the liquefied zinc layer to understand the spreading dynamics. The simulations reveal a displacement of the molten zinc after the impact of the droplet, which ultimately leads to an accumulation of zinc in the outer weld toe after solidification. The simulation approach neglects the effect of evaporating zinc, resulting in a slight overestimation of the final droplet width. However, in terms of spreading initiation during the first milliseconds, the simulation is in good correlation with experimental observations and demonstrates the reason for the good wetting in the presence of zinc coatings.
\end{abstract}

Keywords: laser joining; laser brazing; keyhole brazing; hybrid joint; dissimilar materials; wetting process; computational fluid dynamics; galvanized steel; aluminum

\section{Introduction}

Understanding the wetting behavior of liquefied metal on solid surfaces of other metallic substrates is essential; for example, for laser brazing processes as well as for the thermal joining of dissimilar materials like aluminum and galvanized steel. Especially in case of a novel approach called laser keyhole brazing, overheated braze material must wet substrate surfaces which are not heated directly by the laser irradiation; see [1].

The process efficiency of conventional laser beam brazing is limited due to the absorption efficiency. The absorption of laser energy in case of solid state laser sources like rod, fiber, or disk lasers by solid aluminum material is-depending on the surface topography and temperature-in the range of $4-8 \%$ (e.g., [2]). In laser welding, the amount of absorbed energy can be increased up to $93 \%$ by changing the welding mode from heat conduction welding to deep penetration welding with keyhole (vapor capillary) formation, as shown for example in [3]. The absorption of laser energy in keyhole welding depends, among other parameters, significantly on the keyhole shape (depth, diameter, and curvature). In turn, the keyhole formation and its shape depend on laser process parameters 
like focal diameter, focal position, power density distribution, and process velocity. The approach of keyhole formation known from laser deep penetration welding has been transferred to laser brazing by Radel et al. to increase the amount of absorbed laser energy [1]. In doing so, full penetration of the wire (and thus melting of the base material) had to be prevented by limiting the penetration depth into the filler wire. The keyhole depth was affected by increasing the actual keyhole velocity by beam oscillation. In contrast to conventional laser brazing, the base material must not be irradiated directly by the laser beam to prevent melting due to the high laser power density in case of the keyhole utilization. Thus, the heating of the substrate to the working temperature-needed for suitable wetting and spreading - had to be realized by heat conduction from the overheated filler material in keyhole brazing. Hence, the wetting behavior of overheated filler material on non-heated substrates is one of the main processes for this novel approach of highly efficient laser keyhole brazing. Radel et al. showed for bead-on-plate brazing experiments with aluminum filler wire and galvanized (zinc-coated) steel sheets that laser keyhole brazing is principally possible and that the approach offers high potential for increasing the process efficiency in laser brazing [1].

The joining of dissimilar materials like aluminum and steel by laser beam processes provides a huge potential to realize hybrid lightweight constructions in automotive and naval industries and in the case of aluminum-titanium joints also in the aerospace industry, as shown by Walther et al. [4] and Kocik et al. [5], respectively. Contrary to mechanical techniques such as riveting or clinching, thermal joining processes guarantee a direct material connection; see the overview by Martinsen et al. [6]. The challenge in the thermal joining of aluminum and steel (for example, with brazing or welding) is the poor solubility of $\mathrm{Al}$ and $\mathrm{Fe}$ in solid state, which results in the growth of intermetallic compounds (see e.g., [7]) during the joining processes. Intermetallic compounds are known to be brittle. Hence, excessive melting and mixing of both metals with a conventional welding process was found to be infeasible to produce joints with acceptable mechanical properties. However, the concept of melting only the joining partner with the lower melting temperature (here aluminum) and allowing it to wet the solid surface of the joining partner with the higher melting temperature (here steel) has become a promising approach. In this case, the joint is achieved by a short-time wetting process which is comparable to a continuous brazing process. The mechanical bonding is primarily generated by thermal-induced diffusion. The advantage of this approach is a comparatively low thermal impact on the fusion zone. Thus, the growth of intermetallic compounds can be reduced to a comparatively thin interfacial layer. For example, Achar et al. demonstrated that an intermetallic compound layer thickness of less than $10 \mu \mathrm{m}$ is suitable to guarantee good joint strength for the industrial manufacturing of aluminum-steel joints [8].

The precondition to realize keyhole brazing or such dissimilar joints is the ability of the liquefied metal to spread on the solid surface of the joining partner, meaning that the relation of surface tensions according to Young's formula must be fulfilled. In the case of aluminum and steel, this condition is generally fulfilled, but the natural oxide layer-especially on the aluminum surface (even in liquid state)—inhibits a proper spreading in industrial environments [9]. A possible way to overcome this issue is to apply flux to the fusion zone in order to dissociate oxides, modify the surface tension, and protect the fusion zone from re-oxidation. Most of these fluxes are toxic and corrosive, and must be applied to the fusion zone prior to joining and removed afterwards. These drawbacks limit the acceptance of the described joining technique for industrial applications. Moeller et al. reported an alternative method by using a laser-plasma-hybrid process that allows the removal of the oxide layer by cathodic cleaning and the wetting without any additional flux [10].

It is also well known that zinc coatings on steel surfaces can improve the wetting of aluminum melts, even without flux, as Peyre et al. showed in [11]. In fact, the beneficial effect of zinc coatings on steel surfaces has been observed for several different liquid metals, including copper [12], magnesium [13], or nickel [14]. A mutual observation in each of these cases is an accumulation of zinc that appears near the outer boundary of the weld after solidification. According to Agudo et al. [7], this phenomenon is caused by the fact that the zinc is liquefied and pushed to the side. However, 
little is known about the fluid dynamics taking place inside the melt once it hits the galvanized surface and starts to spread and mix up with the liquefied zinc. Thomy and Vollertsen demonstrated the beneficial effect of zinc coatings on a continuous laser-MIG (metal inert gas) joining process in terms of process stability and resulting seam properties [15]. In [16], the results of a series of single-droplet experiments are reported by Gatzen et al., showing the effect of short-time spreading and solidification of significantly over-heated AlSi12 droplets on different zinc-coated steel substrates. Gatzen et al. [16] demonstrated that the coating type (electro- or hot-dip galvanized) does not affect the general wettability of zinc coatings, and suggested that the interaction between zinc and aluminum is originated by a fluid dynamic rather than by the classical surface tension relation described by Young's formula. An accumulation of zinc along the toe of the solidified droplet was explained with fluid dynamic effect suggested by external observations of the droplets behavior only, and was substantiated by the findings of other authors.

In order to investigate the internal fluid dynamic behavior inside an individual aluminum droplet impinging and spreading on a zinc-coated steel surface and to further substantiate the experimental conclusions of [16], a two-dimensional fluid-dynamic numerical model is applied in this study. The case of an overheated aluminum droplet spreading on a DX56 + Z140 galvanized steel substrate at room temperature $\left(T_{S}=23{ }^{\circ} \mathrm{C}\right)$ is observed experimentally and compared to the corresponding simulation results.

\section{Experimental Method and Simulation Model}

To investigate the spreading process of individual aluminum droplets on commercial galvanized steel substrates, a model experiment has been conducted that provides nearly isolated thermal and dynamic boundary conditions for the generation of liquid droplets. The results of a complete experimental series of single-droplet experiments were reported in [16]. The experimental model system (BIAS GmbH, Bremen, Germany) was designed to investigate short period spreading and solidification characteristics that are typical for laser brazing and dissimilar material joining processes. It consists of a process chamber that is filled with argon (see Figure 1a). To produce liquid droplets, an AlSi12 aluminum wire was constantly fed vertically from the top of the chamber through a wire nozzle, and was horizontally irradiated through a cover glass by a laser beam (TruDisk8002, Trumpf GmbH + Co. KG, Ditzingen, Germany). The defocused laser beam melted the tip of the extending wire, forming a liquid droplet of aluminum. Once the droplet was formed and significantly overheated, it was detached by an abrupt pull-back of the remaining solid wire. Subsequently, the liquid droplet fell from a height of $22 \mathrm{~mm}$ down onto a zinc-coated substrate. The initial substrate temperature was kept at room temperature $\left(T_{S}=23^{\circ} \mathrm{C}\right)$. The spreading process was observed by a high-speed camera (Phantom V5.1, Vision Research Inc., Wayne, NJ, USA) through the observation window in order to track the transient droplet deformation and melt propagation until complete solidification. A defocused two-color pyrometer-spot (IGAR-12 LO, IMPAC Infrared GmbH, Frankfurt, Germany) was also aligned on the substrate surface onto the region of impingement to measure the droplet temperature before its contact with the zinc-coated surface and until solidification. The maximum measured value was defined as the impingement temperature $T_{s, i m}$ of the droplet.

In this study, an aluminum droplet of $110 \mathrm{mg}$ weight was generated and observed while spreading on a hot-dip galvanized steel sheet (DX56 + Z140) that was initially at room temperature. 


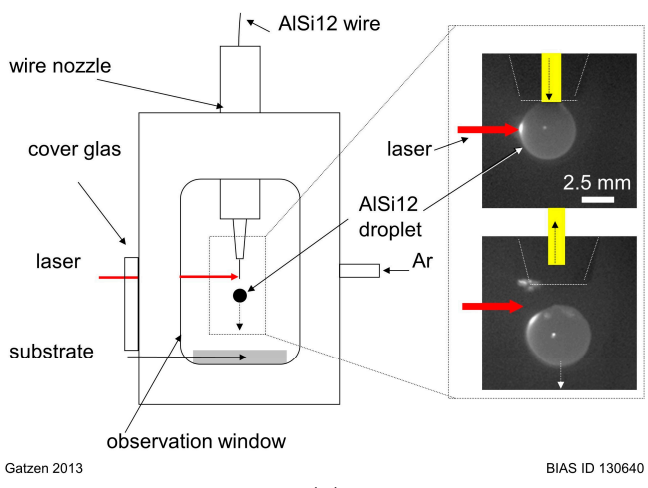

(a)

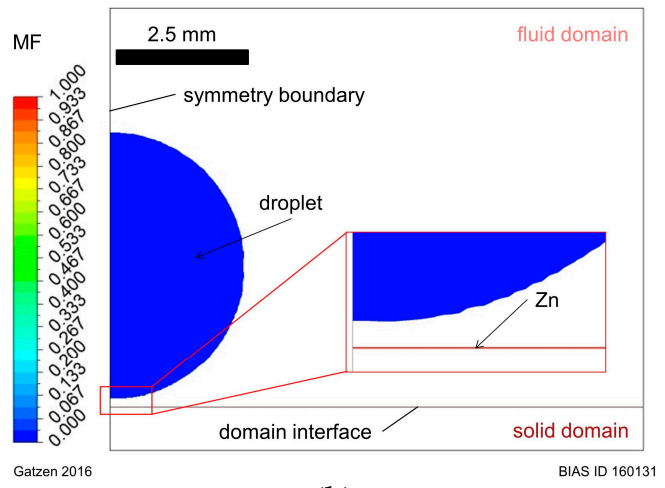

(b)

Figure 1. (a) Experimental model system for single droplet wetting observation; (b) numerical model system and initial conditions for the simulation of single-droplet wetting.

In addition to the experimental observation, a numerical CFD-model (computational fluid dynamics) was designed to calculate the time-dependent fluid-dynamics of the liquid droplet on the zinc-coated substrate. To set up the model and simulate the spreading and solidification process including several different liquid and solid materials, the commercial CFD Toolbox ANSYS CFX ${ }^{\circledR}$ (Ansys Inc., Canonsburg, PA, USA) was used. The software uses the finite-volume method to solve the conservation equations for momentum:

$$
\rho\left(\frac{\partial \vec{v}}{\partial t}+(\vec{v} \cdot \nabla) \vec{v}\right)=-\nabla p+\mu \cdot \nabla^{2} \vec{v}+S_{s o l}
$$

energy

$$
\rho\left(\frac{\partial h}{\partial t}+\nabla \cdot(\vec{v} h)\right)=\nabla \cdot(\lambda \nabla T)
$$

and mass

$$
\frac{\partial \rho}{\partial t}+\nabla \cdot(\rho \vec{v})=0
$$

The values are, respectively: $\vec{v}$ the velocity field, $h$ the static enthalpy, $T$ the temperature field, $p$ the pressure, $\rho$ the density, $\mu$ the dynamic viscosity, and $\lambda$ the thermal conductivity. $S_{\text {sol }}$ describes an additional volume force to model solidification.

Using the symmetries of the problem, a 2D geometry was designed as shown in Figure $1 \mathrm{~b}$. The model geometry represents a fluid and a solid domain, in which the fluid domain contains the liquid aluminum droplet, ambient gas, and the zinc coating which is initially in solid state but is molten during contact with the aluminum droplet. The solid domain contains the steel substrate that remains solid during the whole process, contributing only heat conduction in the energy equation. It is located under the liquid domain and is considered to be in full thermal contact.

In order to reduce the number of phases in the fluid domain to one gaseous and one liquid phase, aluminum and zinc are considered as a single fluid mixture that consists of two components. The composition of the mixture is calculated by an additional conservation equation by defining a mass fraction $(M F)$ as scalar field with values between 0 and 1 . A value of $M F=0$ determines the liquid phase to be aluminum, while a value of $M F=1$ is used to set the fluid properties to those of zinc. Since aluminum and zinc are fully mixable in liquid and solid state, the liquid phase was defined as a binary mixture. Hence, a linear dependency for the intermediate values of dynamic viscosity, density, and thermal conductivity on the $M F$ is considered.

To simulate the free surface between liquid and gaseous phase, the so-called volume fraction field $(V F)$ was calculated by an additional conservation equation. The $V F$ is used to track the free interface and to apply surface tension forces to it. 
The volume force $S_{\text {sol }}$ was added to the momentum equation to simulate solidification of the liquid phase by following the relation:

$$
S_{s o l}=C_{0}\left(\frac{\left(1-f_{l}\right)^{2}}{\left(f_{l}^{3}+0.1\right)}\right)
$$

where $f_{l}$ is the so-called liquid fraction that depends on the liquidus temperature $T_{L}$ and the solidus temperature $T_{S}$ of the mixture:

$$
f_{l}=\left[\begin{array}{cc}
1 & T=T_{L} \\
T-T_{S} & T_{L}<T<T_{S} \\
T_{L}-T_{S} & T=T_{S} \\
0 &
\end{array}\right.
$$

$C_{0}$ is a negative constant of high value that allows the volume force to dominate the momentum equation, reducing the velocity to zero once the maximum force is reached. A modified heat capacity was used to consider latent heat during solidification and melting:

$$
c_{p, e f f}=c_{p, 0}+\frac{e^{-\left(\frac{\left(T-0.5\left(T_{L}-T_{S}\right)\right)}{\left(T_{L}-T_{S}\right)^{2}}\right)}}{\sqrt{\pi}\left(T_{L}-T_{S}\right)} \Delta H .
$$

$c_{p, 0}$ is the original unmodified heat capacity and $\Delta H$ is the latent heat of melting.

Figure $1 \mathrm{~b}$ also shows the initial conditions for the $V F$ and the $M F$. The liquid phase with a $V F=1$ is represented by the colored areas in the domain. The liquid phase is divided in a droplet geometry placed about $0.2 \mathrm{~mm}$ above the surface and a small $9.85 \mu \mathrm{m}$-thick layer directly on the bottom surface of the fluid domain. The color of the areas represents the local $M F$. For the droplet geometry, the $M F$ was set to zero, representing the liquid aluminum, and to 1 for the zinc. The layer thickness is comparable to the thickness of a Z140 zinc coating. The initial velocity of the droplet phase was set to a value of about $0.57 \mathrm{~m} / \mathrm{s}$ to consider the gravitational acceleration of the droplet during its fall from of a height of $22 \mathrm{~mm}$. The initial temperature of the droplet was set to $1400^{\circ} \mathrm{C}$, while the temperature of the zinc layer, gas and the solid domain was set to a value of $23^{\circ} \mathrm{C}$.

Instead of adhesive forces [17], free slip boundary conditions were used at the interface between liquid and solid domains. Table 1 gives the material and model parameters for the calculation.

Table 1. Material and model parameters.

\begin{tabular}{ccc}
\hline Parameter & Value & Unit \\
\hline Density Al $\rho_{A l}$ & 2385 & $\mathrm{~kg} / \mathrm{m}^{3}$ \\
Density Zn $\rho_{Z n}$ & 6600 & $\mathrm{~kg} / \mathrm{m}^{3}$ \\
Density Steel $\rho_{S t}$ & 7854 & $\mathrm{~kg} / \mathrm{m}^{3}$ \\
Density Gas $\rho_{g a s}$ & 1.185 & $\mathrm{~kg} / \mathrm{m}^{3}$ \\
Thermal Conductivity Al $\lambda_{A l}$ & 95 & $\mathrm{~W} /(\mathrm{m} \mathrm{K})$ \\
Thermal Conductivity Zn $\lambda_{Z n}$ & 113 & $\mathrm{~W} /(\mathrm{m} \mathrm{K})$ \\
Thermal Conductivity Steel $\lambda_{S t}$ & 60.5 & $\mathrm{~W} /(\mathrm{m} \mathrm{K})$ \\
Thermal Conductivity Gas $\lambda_{g a s}$ & 0.0261 & $\mathrm{~W} /(\mathrm{m} \mathrm{K})$ \\
Dynamic Viscosity Al $\mu_{A l}$ & 0.0013 & $\mathrm{~kg} /(\mathrm{m} \mathrm{s})$ \\
Dynamic Viscosity Zn $\mu_{Z n}$ & 0.00385 & $\mathrm{~kg} /(\mathrm{m} \mathrm{s})$ \\
Dynamic Viscosity Gas $\mu_{g a s}$ & 0.0000183 & $\mathrm{~kg} /(\mathrm{m} \mathrm{s})$ \\
Specific Heat Capacity Al $c_{p, 0, A l}$ & 900 & $\mathrm{~J} /(\mathrm{kg} \mathrm{K})$ \\
Specific Heat Capacity Zn $c_{p, 0, Z n}$ & 390 & $\mathrm{~J} /(\mathrm{kg} \mathrm{K})$ \\
Specific Heat Capacity Steel $c_{p, 0, S t}$ & 434 & $\mathrm{~J} /(\mathrm{kg} \mathrm{K})$ \\
Specific Heat Capacity Gas $c_{p, 0, g a s}$ & 1004 & $\mathrm{~J} /(\mathrm{kg} \mathrm{K})$ \\
Solidification Constant $C_{0}$ & $-10^{8}$ & - \\
Latent Heat of Melting $\Delta H$ & 398 & $\mathrm{~kJ} / \mathrm{kg}$ \\
\hline
\end{tabular}


The liquidus temperature $T_{L}$ and the solidus temperature $T_{S}$ are determined according to the binary system Al-Zn. For simplification, both temperatures are considered as an offset value of the temperature $T_{\text {Solidification }}$. They are shown in Figure 2 in dependence of the $M F$ of zinc.

For this study, the model was used to simulate a liquid aluminum droplet spreading on a zinc layer which is initially at room temperature but molten during contact with the overheated melt. From the results of the transient simulation, the time-dependent droplet evolution (especially the wetting length) and the zinc distribution inside the melt until its solidification were analyzed.

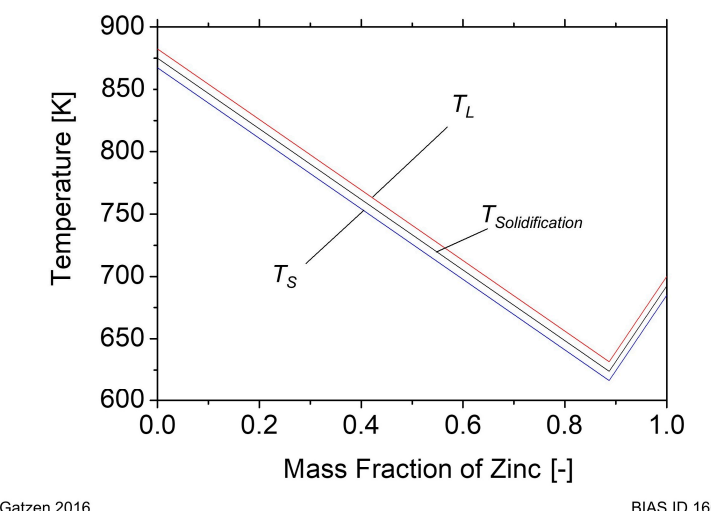

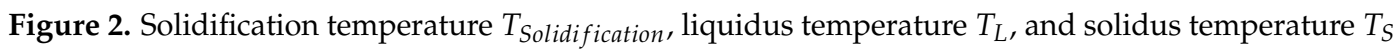
used for the simulation.

\section{Results}

Figure 3 shows the comparison of experimental und simulated droplet evolution in a series of pictures during impingement and spreading for a total time of $9 \mathrm{~ms}$. The droplet shape recorded with the high-speed camera is shown on the left hand side of each picture, while the respective simulation result of the liquid phase, colored by the $M F$, is given on the right hand side.

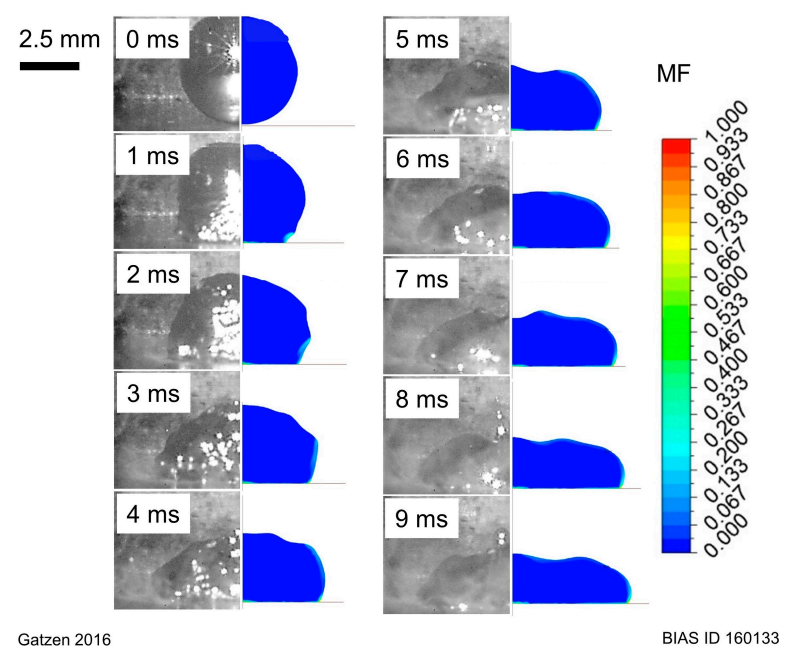

Figure 3. Droplet evolution on the zinc-coated surface, comparison between experiment and simulation.

The droplet immediately started to spread on the surface after impingement. After about $3 \mathrm{~ms}$, excessive evaporation could be observed in the experiment. Small surface waves occurred on the spherical cap during spreading, but the droplet stayed intact. No detachment or spatters can be observed in the high-speed images. The simulation results show that the zinc was molten and pushed 
away to the side by the propagating melt front. The shape of the simulated liquid fits the observed droplet shape in the experiment very well, at least up to a time of about $5 \mathrm{~ms}$.

The transient spreading width $b_{d}(t)$ was measured for both the experimentally observed and simulated droplets to quantify the spreading process, see Figure 4 . The spreading width describes the diameter of the propagating droplet at the interface. The measured droplet reached its maximum widths of $8 \mathrm{~mm}$ after a short period of $5 \mathrm{~ms}$, while the simulated droplet expanded to a maximum width of $12 \mathrm{~mm}$ over a time of about $15 \mathrm{~ms}$. Hence, the simulation overestimates the final spreading width in the experiment and the initiation of solidification.

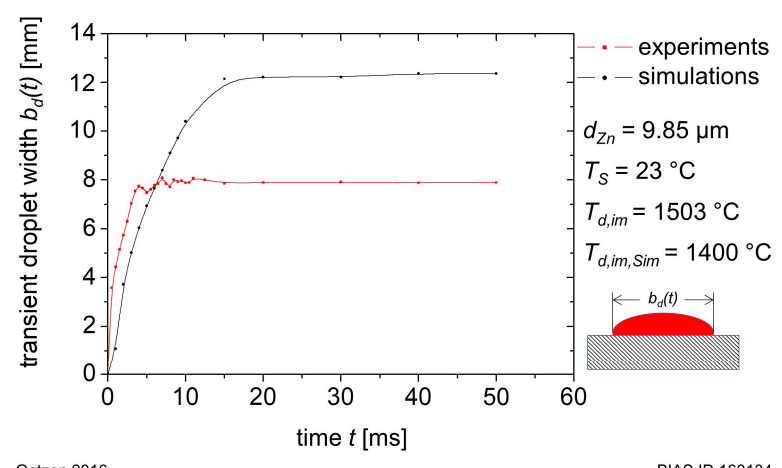

Figure 4. Comparison between measured and simulated transient droplet width.

The zinc layer is partially molten during the first contact with the overheated liquid aluminum. Figure 5 shows the simulated droplet $50 \mathrm{~ms}$ after impact. The outer boundary of the aluminum deposit is already solidified. Zinc was accumulated around the weld toe. However, the zinc layer was not completely pushed to the side by the propagating melt front. The remaining zinc was comparatively slowly molten and dissolved by diffusive and convective mass transfer until the droplet was fully solidified.

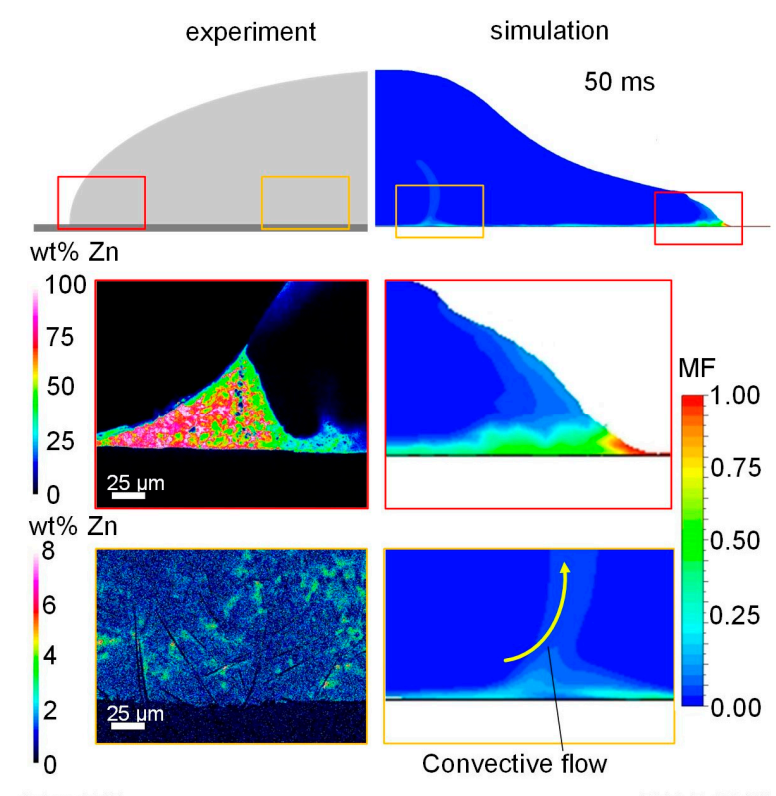

Figure 5. Simulated zinc distribution (mass fraction, $M F$ ) near the weld toe that is already solidified and near the middle of the droplet that is still liquid compared to WDS (wavelength-dispersive X-ray spectroscopy) scans of the same zones on the cross-sections of the completely solidified droplet from the wetting experiment. 
Figure 5 also shows WDS analysis (wavelength-dispersive X-ray spectroscopy) (Electron Microprobe Analysis, JEOL, Tokyo, Japan) of metallographic sections from the experimentally produced droplet, where the two-dimensional distribution of zinc has been analyzed. This projection is comparable to the mass fraction $(M F)$ of zinc of the already-solidified weld toe of the simulated droplet. Similar to the simulation results, an accumulation of zinc around the weld toe could be found, while along the inner interface, the zinc layer was completely molten and formed an aluminum-zinc alloy.

\section{Discussion}

The general effect of spreading on liquefied zinc-coatings could be demonstrated both experimentally and numerically. Since no specific adhesive forces are considered between aluminum and zinc, the spreading seen by the simulation results is only generated by fluid dynamic interaction and gravitation. Hence, considering only fluid dynamic effects, the simulation seems to fit the experimentally observed spreading in the first $5 \mathrm{~ms}$. During this time, the zinc layer is partially molten and the impinging droplet can propagate on a liquid surface.

However, the overestimation of spreading in the numerical model could be linked to a slower solidification. This might be caused by the heat loss of the evaporated zinc that is not yet considered in the simulation. The assumption that this heat loss plays a major role in the overall heat exchange is based on the experimentally observed excessive evaporation of zinc. Moreover, a straightforward analytical estimation for energy consumption by evaporating zinc in the case of bead-on-plate brazing of aluminum on zinc-coated steel, given in [18], shows a clear correlation with characteristic spreading times for different zinc coating thicknesses, suggesting a significant contribution of heat loss due to evaporating zinc in a very similar case to that discussed here. Depending on the applied line energy and zinc coating thickness, total energy losses between $9 \%$ and $21 \%$ were estimated for bead-on-plate laser brazing [18]. In addition to the heat loss due zinc evaporation, the spreading width could be affected by the zinc coating acting as a surfactant which covers the classical bare solid-air interface with effects on the wetting length and angle [19].

The triangular-shaped accumulation of zinc in the weld toe-which has also been observed for other materials spreading on zinc coatings-stems from the initially molten zinc layer that is pushed to the side by the propagating melt front. The remaining zinc layer seems to be either evaporated or completely distributed in the surrounding aluminum melt, leaving no zinc layer along almost the entire interface. As this process occurs exclusively between solid and liquid phases, it is concluded that it leaves behind a clean, oxide-free surface, being the basis for the wetting process between aluminum and steel.

The simulation results also substantiate the assumption that the wetting process on zinc layers is basically determined by the thermal conditions (i.e., by the time when zinc, aluminum, and local aluminum-zinc alloy are liquid). Hence, the resulting wetting angle and length are determined by the solidification of the propagating melt front rather than by any surface tension relation.

\section{Summary}

We demonstrated the spreading behavior of individual over-heated aluminum droplets on zinc-coated steel surfaces at room temperature both experimentally and numerically. The spreading process starts as soon as the droplet hits the solid zinc surface and melts the zinc coating. The propagating melt front consists of a local aluminum-zinc alloy and is stopped as soon as the temperature is below the local melting temperature. A zinc accumulation is formed at the weld toe. It stems from molten zinc that is pushed to the side by the propagating melt front generating a local aluminum-zinc alloy.

In the current state, the numerical model overestimates the wetting length since the cooling of the simulated droplet neglects the effect of evaporating zinc. Hence, the experimentally observed droplet stops spreading after $5 \mathrm{~ms}$, while the simulated droplet reaches its final width after $15 \mathrm{~ms}$. However, 
the simulation in conjunction with the experimental observation substantiates the assumption of a fluid dynamic origin of the interaction between liquid aluminum droplets and zinc coatings.

Acknowledgments: This work was accomplished within the Center of Competence for Welding of Aluminum Alloys - CentrAl. The authors gratefully acknowledge the funding (VO530/109-1 "Energy efficient brazing by using the deep penetration effect") by the Deutsche Forschungsgemeinschaft DFG (German research foundation).

Author Contributions: Claus Thomy, Frank Vollertsen and Marius Gatzen conceived the experiments and simulations; Marius Gatzen designed and performed the simulations; Marius Gatzen and Tim Radel performed the experiments; Marius Gatzen, Tim Radel and Peer Woizeschke analyzed the data; Marius Gatzen, Peer Woizeschke and Frank Vollertsen wrote the paper.

Conflicts of Interest: The authors declare no conflict of interest. The funding sponsors had no role in the design of the study; in the collection, analyses, or interpretation of data; in the writing of the manuscript, and in the decision to publish the results.

\section{References}

1. Radel, T.; Woizeschke, P.; Vollertsen, F. Keyhole Brazing-An Approach for Energy Efficient Brazing by Using the Deep Penetration Effect; LÖT 2016, DVS Reports; DVS Media GmbH: Düsseldorf, Germany, 2016; Volume 325, pp. 302-306.

2. Dausinger, F. Strahlwerkzeug Laser: Energiekopplung und Prozesseffektivität; Teubner: Stuttgart, Germany, 1995. (In German)

3. Kawahito, Y.; Matsumoto, N.; Abe, Y.; Katayama, S. Relationship of laser absorption to keyhole behavior in high power fiber laser welding of stainless steel and aluminum alloy. J. Mater. Process. Technol. 2011, 211, 1563-1568. [CrossRef]

4. Walther, R.; Thomy, C.; Möller, F.; Vollertsen, F. Thermisches Fügen von Mischverbindungen. In 6. Laseranwenderforum (LAF'08); Vollertsen, F., Seefeld, T., Eds.; BIAS-Verlag: Bremen, Germany, 2008; Volume 36, pp. 37-49. (In German)

5. Kocik, R.; Vugrin, T.; Seefeld, T. Laserschweißen im Flugzeugbau: Stand und künftige Anwendungen. In Laserstrahlfügen: Prozesse, Systeme, Anwendungen, Trends; Vollertsen, F., Seefeld, T., Eds.; BIAS-Verlag: Bremen, Germany, 2006; Volume 28, pp. 15-26. (In German)

6. Martinsen, K.; Hu, S.J.; Carlson, B.E. Joining of dissimilar materials. CIRP Ann. Manuf. Technol. 2015, 64, 679-699. [CrossRef]

7. Agudo, L.; Eyidi, D.; Schmaranzer, C.H.; Arenholz, E.; Jank, N.; Bruckner, J.; Pyzalla, A.R. Intermetallic $\mathrm{Fe}_{x} \mathrm{Al}_{y}$-phases in a steel/Al-alloy fusion weld. J. Mater. Sci. 2007, 42, 4205-4214. [CrossRef]

8. Achar, D.R.G.; Ruge, J.; Sundaresan, S. Metallurgical and mechanical investigations of aluminium-steel welds (III). Aluminium 1980, 56, 533-536.

9. Jia, L.; Jiang, J.; Shi, Y.; Ni, C.; Chen, J.; Huang, G. Effect of zinc on the laser welding of an aluminium alloy and galvanized steel. J. Mater. Process. Technol. 2015, 224, 49-59. [CrossRef]

10. Möller, F.; Thomy, C.; Vollertsen, F. Development of a plasma-laser brazing process for fluxless joining of aluminium to steel. In Laser in Manufacturing (LiM09); Ostendorf, A., Graf, T., Petring, D., Otto, A., Vollertsen, F., Eds.; AT-Fachverlag: Stuttgart, Germany, 2009; pp. 83-88.

11. Peyre, P.; Sierra, G.; Deschaux-Beaume, F.; Stuart, D.; Fras, G. Generation of aluminium-steel joints with laser-induced reactive wetting. Mater. Sci. Eng. A 2007, 444, 327-338. [CrossRef]

12. Koltsov, A.; Bailly, N.; Cretteur, L. Wetting and laser brazing of Zn-coated steel products by Cu-Si filler metal. J. Mater. Sci. 2010, 45, 2118-2125. [CrossRef]

13. Tan, C.W.; Li, L.Q.; Chen, Y.B.; Mei, C.X.; Guo, W. Interfacial microstructure and fracture behaviour of laser welded-brazed Mg alloy to zinc coated steel. Int. J. Adv. Manuf. Technol. 2013, 68, 1179-1188. [CrossRef]

14. Govekar, E.; Jeric, A.; Weigl, M.; Schmidt, M. Laser droplet generation: Application to droplet joining. CIRP Ann. Manuf. Technol. 2009, 58, 205-208. [CrossRef]

15. Thomy, C.; Vollertsen, F. Laser-MIG hybrid welding of aluminium to steel-Effect of process parameters on joint properties. Weld. World 2012, 56, 124-132. [CrossRef]

16. Gatzen, M.; Radel, T.; Thomy, C.; Vollertsen, F. Wetting behavior of eutectic Al-Si droplets on zinc coated steel substrate. J. Mater. Process. Technol. 2014, 214, 123-131. [CrossRef] 
17. Tadmor, R.; Das, R.; Gulec, S.; Liu, J.; N'guessan, H.E.; Shab, M.; Wasnik, P.S.; Yadav, S.B. Solid-Liquid Work of Adhesion. Langmuir 2017, 33, 3594-3600. [CrossRef] [PubMed]

18. Gatzen, M.; Radel, T.; Thomy, C.; Vollertsen, F. Wetting and solidification characteristics of aluminium on zinc coated steel in laser welding and brazing. J. Mater. Process. Technol. 2016, 238, 352-360. [CrossRef]

19. Tadmor, R. Drops that pull themselves up. Surf. Sci. 2014, 628, 17-20. [CrossRef]

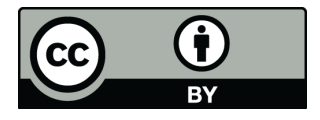

(c) 2017 by the authors. Licensee MDPI, Basel, Switzerland. This article is an open access article distributed under the terms and conditions of the Creative Commons Attribution (CC BY) license (http://creativecommons.org/licenses/by/4.0/). 